Check for updates

Cite this: RSC Adv., 2017, 7, 37324

Received 16th May 2017

Accepted 19th July 2017

DOI: $10.1039 / \mathrm{c} 7 \mathrm{ra05524b}$

rsc.li/rsc-advances

\section{Highly fouling-resistant brominated poly(phenylene oxide) membranes using surface grafted diethylenetriamine $\uparrow$}

\author{
Muayad Al-Shaeli, ${ }^{a}$ Stefan J. D. Smith, (D) ab Ezzatollah Shamsaei, ${ }^{a}$ Huanting Wang, (D) ${ }^{a}$ \\ Kaisong Zhang ${ }^{C}$ and Bradley P. Ladewig (D) *d
}

Hydrophilic bromomethylated poly(phenylene oxide) (BPPO) ultrafiltration membranes were prepared via a single-step reaction with diethylenetriamine (DETA). The resulting DETA modified BPPO membranes are characterised using FTIR-ATR, SEM, fouling resistance, filtration test and contact angle measurements. Although permeation flux was adversely affected, the chemically bound DETA leads to a significant increase in surface hydrophilicity and anti-fouling properties of BPPO/DETA membranes. The composite BPPO/DETA membranes show a considerable reduction in membrane fouling and enhanced BSA rejection, with foulants easily removed by normal cleaning methods. Herein, a facile surface modification with DETA is shown to be an effective means of enhancing the flux recovery ratio and anti-fouling properties of BPPO membranes.

\section{Introduction}

Membranes have been widely applied in the field of water treatment, with extensive applications in water purification, desalination, and wastewater treatment. ${ }^{1,2}$ Membrane characteristics such as, surface hydrophilicity, porosity and antifouling properties are critically important in these separation processes. Ultrafiltration membranes (with pore sizes 2-100 $\mathrm{nm})$ are widely used in different industrial applications, including applications of water and wastewater treatment; however, fouling remains a stubborn problem that restricts their widespread application. ${ }^{1,3-11}$ Most of the commercial UF membranes used in wastewater treatments are made from hydrophobic polymers such as, polyethersulfone (PES), poly(vinylidene fluoride) (PVDF), polysulfone (Psf) and polyacrylonitrile (PAN) $)^{12,13}$ which are particularly susceptible to membrane fouling. During filtration processes, deposition of foulants (e.g. proteins in solution) on membrane surfaces leads to drastic flux decline, shortened operational life, increased cleaning requirements and higher replacement and operational costs. ${ }^{1-16}$ Therefore, membranes with anti-fouling surfaces have considerable potential to improve the water permeation

\footnotetext{
${ }^{a}$ Department of Chemical Engineering, Monash University, VIC 3800, Australia ${ }^{b}$ CSIRO, Private Bag 10, Clayton South MDC, VIC 3169, Australia

'Key Laboratory of Urban Pollutant Conversion, Institute of Urban Environment, Chinese Academy of Sciences, Xiamen 361021, China

${ }^{d}$ Barrer Centre, Department of Chemical Engineering, Imperial College London, Exhibition Road, SW7 2AZ, London, UK. E-mail: b.ladewig@imperial.ac.uk

$\dagger$ Electronic supplementary information (ESI) available. See DOI: $10.1039 / \mathrm{c} 7 \mathrm{ra} 05524 \mathrm{~b}$
}

and performance of these processes. The hydrophilic modification of membrane surfaces is a an effective way to improve their permeability and anti-fouling properties as the hydrophilic groups can facilitates an enhancement in water flux, reduce the flow resistance and help prevents the adhesions of pollutants on the membrane surfaces. ${ }^{17-23}$

Recently, a number of techniques have been investigated to improve the hydrophilicity and anti-fouling performance of membranes including grafting hydrophilic species to the top surface of pre-formed ultrafiltration membranes, ${ }^{24,25}$ hydrophilic polymer coatings ${ }^{26-28}$ cold plasma treatment, ${ }^{29-33}$ covalent attachment of hydrophilic polymers, ${ }^{34,35}$ and incorporating hydrophilic fillers such as inorganic nanoparticles. ${ }^{36}$ Among these methods, grafting hydrophilic molecules to the top surface of membranes is a simple, practical and economical addition to existing membrane manufacturing processes, without requiring heat treatment or any other hazardous conditions. ${ }^{37}$

Brominated poly(phenylene oxide) (BPPO) is an outstanding ultrafiltration polymer with high glass transition temperature $\left(210^{\circ} \mathrm{C}\right)$, excellent membrane forming properties, good thermal and mechanical strength, and excellent chemical stability. ${ }^{38-40} \mathrm{It}$ is commonly available and has been used to prepare ultrafiltration membranes with high permeation rate (high water flux). ${ }^{41}$ Despite these inherent material advantages, the hydrophobic nature of BPPO membranes makes them highly susceptible to fouling, which with their usually modest water permeability, proves a significant limitation in their application to water filtration. ${ }^{45}$

Compared to other UF polymers such as polyethersulfone (PES), poly(vinylidene fluoride) (PVDF), polysulfone (Psf) and 
polyacrylonitrile (PAN), BPPO contains a highly reactive groups $\left(-\mathrm{CH}_{2} \mathrm{Br}\right)$ group that can react directly with imidazole or amine species without the need to use a cross-linker or pre-treatment the membrane. ${ }^{\mathbf{4 2 - 4 4}}$

This reactivity enables BPPO membranes to be readily chemically altered to induce controlled levels of hydrophilicity, excellent separation efficiency, and high rate of water permeation. ${ }^{\mathbf{1 8 - 2 0}}$ Feng et $a l .{ }^{37}$ modified the surface of BPPO UF membranes using chitosan as grafting agent. The modified BPPO membrane showed a slight decrease in water permeation after $6 \mathrm{~h}$ grafting duration. The chitosan-modified BPPO membranes showed an improved in anti-fouling performance with $85 \%$ flux recovery ratio. Using a more complicated approach, Lin et al. ${ }^{46}$ prepared a novel ultrafiltration BPPO/TPPOQP-Br via a phase inversion method and found that a membrane modified with TPPOQP-Br showed higher permeability (water flux) while maintaining higher rejection properties in the resulting ultrafiltration membranes. Similarly, Yang et $a l^{47}$ incorporated polyethyleneimine factionalised graphene oxide (GO) into BPPO ultrafiltration membrane matrix by a covalent bond interaction (nucleophilic reaction) between PEI and benzyl bromide of BPPO. Then a crosslinking network of PEI-GO/BPPO was obtained to provide a route for the water passing rapidly through. The composite PEI-GO/BPPO membranes exhibited a highly improved in permeation rate (6 times higher) compared with the pristine BPPO membranes. In each case, the modified BPPO membranes showed higher porosity, surface hydrophilicity, and improved anti-fouling properties.

In this study, diethylenetriamine (DETA) chosen for the hydrophilic modification of BPPO UF membranes because of its (1) relatively low volatility, (2) reactive primary and secondary amine, (3) commercial availability, and (4) solubility in polar organic solvents. Previously, DETA has been used in various applications, including gas separations $\left(\mathrm{H}_{2} / \mathrm{CO}_{2}\right)$, epoxy adhesives and in the petrochemical industry. ${ }^{48}$

In this work, DETA was grafted on the top surface of BPPO UF membranes using a direct single step reaction as depicted in Scheme 1.
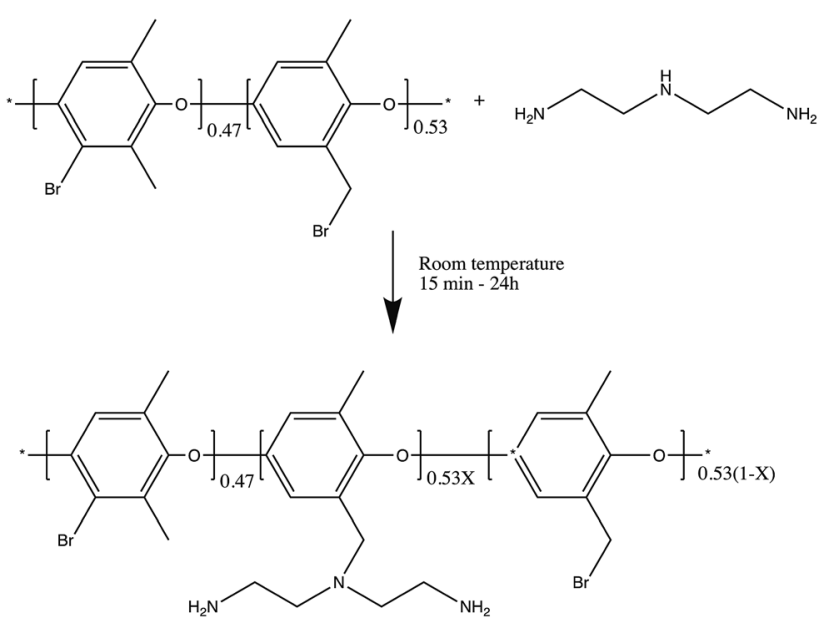

Scheme 1 The chemical reaction between BPPO and DETA, where $X$ represents the extent of reaction between BPPO and DETA.

\section{Experimental}

\section{Materials}

Bromomethylated poly(phenylene oxide) (BPPO, MW = 60500$)$ with aryl substitution degree of 0.47 and benzyl substitution degree of 0.53 was purchased from Tianwei Membrane Corporation Ltd. (Shandong, China). $\mathrm{NaOH}$ (purity $\geq 99 \%$ ) was obtained from Merck KGaA Company (Germany). Diethylenetriamine (DETA) (purity, $\geq 99 \%$ ), and 1-methyl-2-pyrrolidone (NMP, purity $\geq 99 \%$ ) were obtained from Sigma-Aldrich, Australia. Poly(ethylene glycol) (PEG) with different molecular weights (35 kDa, $100 \mathrm{kDa}, 200 \mathrm{kDa}$ ) was obtained from Sigma-Aldrich, Australia and used without purification. Bovine Serum Albumin (BSA) was obtained from Sigma-Aldrich Australia and used as model foulant. Milli-Q water was used in the experiments with a resistivity of $18.2 \mathrm{M} \Omega \mathrm{cm}^{-1}$. Distilled water (DI) was provided a water distillation unit (Labglass Aqua III).

\section{Membrane preparation}

BPPO UF membranes were prepared using a Phase inversion casting method. A $40 \mathrm{~mL}$ casting solution was prepared by stirring $20 \mathrm{wt} \%$ BPPO polymer in $80 \mathrm{wt} \%$ NMP solvent for $24 \mathrm{~h}$ using magnetic stirrer at $200 \mathrm{rpm}$. Afterward, the homogenous casting solution was left overnight in the fume cupboard to release air bubbles. The casting solution was then spread uniformly on a cleaned glass plate and cast using a casting knife (Paul Gardner CO., Inc. USA) with a $150 \mu \mathrm{m}$ air gap. The membranes were then immersed in a coagulation bath of deionized water (DI). After peeling the membranes off from the glass plate, they were removed from the coagulation bath and washed three times with DDI and stored in fresh double deionized water (DDI) for at least one day before use. ${ }^{\mathbf{4 9 , 5 0}}$

To prepare BPPO/DETA composite membranes, the BPPO membrane was exposed to a $1 \mathrm{M}$ solution of DETA in $\mathrm{H}_{2} \mathrm{O}$ by floating the BPPO membrane so only the top surface contacted the DETA solution. The reaction temperature was held constant at room temperature while the reaction time was varied from 15 min to $24 \mathrm{~h}$. Afterward; the composite BPPO membranes were washed three times with DI water and then stored in fresh DI water for at least one day before use. The composite membranes were denoted according to the grafting period BPPO/DETA15 min, BPPO/DETA-30 min, BPPO/DETA-1 h, BPPO/DETA-1.5 h, BPPO/DETA-2 h, BPPO/DETA-3 h, BPPO/DETA-4 h, BPPO/DETA5 h, BPPO/DETA-6 h, BPPO/DETA-12 h, BPPO/DETA-24 h.

\section{FTIR and contact angle measurements}

The modified and unmodified BPPO membranes were characterised by Fourier Transform Infrared spectroscopy in the range of $4000-600 \mathrm{~cm}^{-1}$ at a resolution of $4 \mathrm{~cm}^{-1}$ and averaged from 64 scans. The surface morphology of BPPO and DETA/BPPO membranes were examined by scanning electron microscopy (SEM) (Magellan SEM, FEI Company, America). The hydrophilicity of BPPO membranes was determined with contact anglemeasuring instrument (video based optical contact angle measuring instrument, OCA-15EC, Dataphysics, Germany) using $5 \mu \mathrm{L}$ of water, dropped from the syringe onto the top surface of 
modified and unmodified BPPO membranes. Results have been averaged from, at least five contact angle measurements at different locations for each membrane. The porosity of membranes was calculated by mass difference between the membrane soaked in water for $3 \mathrm{~h}$ and after drying in vacuum oven at $60{ }^{\circ} \mathrm{C}$. Membrane porosity was calculated according eqn (1): $:^{51,52}$

$$
\varepsilon=\frac{\frac{W_{\mathrm{w}}-W_{\mathrm{D}}}{D_{\mathrm{w}}}}{\frac{W_{\mathrm{w}}-W_{\mathrm{D}}}{D_{\mathrm{W}}}+\frac{W_{\mathrm{D}}}{D_{\mathrm{p}}}}
$$

where $W_{\mathrm{w}}$ is the weight of the wet membrane $(\mathrm{g})$ and $W_{\mathrm{D}}$ is the weight of the dry membrane $(\mathrm{g}) . D_{\mathrm{p}}$ and $D_{\mathrm{w}}$ are the densities of the polymer and water $\left(\mathrm{g} \mathrm{cc}^{-1}\right)$.

\section{Permeation and molecular weight cut-off}

The pure water flux (PWF) of the unmodified BPPO and BPPO/ DETA composite membranes were measured using dead-end cell filtration unit (HP4750 stirred cell, Sterlitech, USA) with membrane samples cut to a diameter of $49 \mathrm{~mm}$ to effective membrane area of $14.6 \mathrm{~cm}^{2}$. The filtration cell was filled with $300 \mathrm{~mL}$ double deionized water (DDI) and then connected to $5 \mathrm{~L}$ dispensing vessel with compressed nitrogen gas used to control the feed pressure. The collected permeate was determined using an electronic balance with mass change recorded automatically with connected Labview software. During filtrations test, membrane samples are pre-compacted first at $150 \mathrm{kPa}$ for at least $1 \mathrm{~h}$ to stabilise the flux, which is then recorded at a pressure of $100 \mathrm{kPa}$. Reported flux values are averaged from tests using at least five membrane samples.

Molecular weight cut-off (MWCO) and solute rejection was determined using a series of $1 \mathrm{~g} \mathrm{~L}^{-1}$ of polyethylene glycol (PEG) solution, prepared by dissolving PEG of different molecular weights $(35,100,200 \mathrm{kDa})$ in deionized water (DI). The PEG rejection rates were calculated by measuring the concentrations of PEG solution in the feed solution $\left(C_{\mathrm{f}}\right)$ and permeate water $\left(C_{\mathrm{P}}\right)$ using a total organic carbon analyser (TOC-LCSH, Shimadzu, Japan) using eqn (2): ${ }^{53}$

$$
R=\left(1-C_{\mathrm{P}} / C_{\mathrm{f}}\right) \times 100
$$

The pore size of the membranes was then estimated based on the values of MWCO of the membrane according to the eqn (3): ${ }^{55}$

$$
r=0.0262 \sqrt{\mathrm{MWCO}}-0.3
$$

where $r=$ pore size of membrane $(\mathrm{nm}), \mathrm{MWCO}=$ molecular weight cut-off $\left(\mathrm{g} \mathrm{mol}^{-1}\right)$. MWCO was calculated by interpolating measured rejection rate to a rejection of $90 \%$.

\section{Fouling measurements}

Constant flux fouling mode was used in this study to determine the fouling resistance of the membranes. ${ }^{56}$ The membrane samples were first pre-compacted by double deionised water at $150 \mathrm{kPa}$ for at least $1 \mathrm{~h}$. Then, DDI water was exchanged for a BSA protein solution $\left(0.5 \mathrm{~g} \mathrm{~L}^{-1}\right.$, prepared using phosphate buffer, $\mathrm{pH}=7.4)$. During the fouling test, the flux was fixed at approximately $40 \mathrm{LMH}$ for $2 \mathrm{~h}$ using a peristaltic pump (L/S Digital Drive, L/S Easy-Load 3 pump head, and peroxide-cured silicone tubing, L/S 13, Masterflex, USA). The transmembrane pressure (TMP) was recoded each $30 \mathrm{~s}$ using two pressure transducers. After testing, the fouled membranes were physically and chemically cleaned. For physical cleaning, the membranes in the filtration cell were rinsed twice with DDI for 20 min. The membrane flux after physical cleaning was recorded from the lab view software at $100 \mathrm{kPa}$.

For chemical cleaning, $100 \mathrm{~mL}$ of $\mathrm{NaOH}$ solution $\left(2 \mathrm{~g} \mathrm{~L}^{-1}, \mathrm{pH}\right.$ $=12$ ) was added to the filtration cell and stirred for $20 \mathrm{~min}$ before being rinsed three times with DDI to wash off the $\mathrm{NaOH}$ solution. After chemical cleaning step, the membrane flux was recorded at $100 \mathrm{kPa}$. Chemical cleaning performance was monitored over three fouling and cleaning cycles, with membrane flux recorded after each cycle.

To determine the performance of membranes, flux recovery ratio of membranes was calculated by comparing the flux after each cleaning cycle to the flux before fouling.

As a measure of fouling behaviour, membrane resistances were estimated using the following eqn (4-7): ${ }^{54}$

$$
\begin{gathered}
R_{\mathrm{t}}=R_{\mathrm{m}}+R_{\mathrm{ir}}+R_{\mathrm{r}} \\
R_{\mathrm{m}}=\frac{\mathrm{TMP}}{\mu \mathrm{J}_{\mathrm{BF}}} \\
R_{\mathrm{ir}}=\frac{\mathrm{TMP}}{\mu \mathrm{J}_{\mathrm{AF}}}-R_{\mathrm{m}} \\
R_{\mathrm{r}}=\frac{\mathrm{TMP}^{\prime}}{\mu \mathrm{J}_{\mathrm{f}}}-R_{\mathrm{m}}-R_{\mathrm{ir}}
\end{gathered}
$$

where $R_{\mathrm{t}}=$ total resistance, $R_{\mathrm{m}}=$ intrinsic membrane resistance, $R_{\mathrm{ir}}=$ irreversible membrane resistance, $R_{\mathrm{r}}=$ reversible membrane resistance, TMP $=$ transmembrane pressure $(100$ $\mathrm{kPa}), \mu=$ permeate viscosity, $J_{\mathrm{BF}}=$ pure water flux before fouling, $J_{\mathrm{AF}}=$ pure water flux after fouling (after the membrane is physically and chemically cleaned), $\mathrm{TMP}^{\prime}=$ transmembrane pressure after $2 \mathrm{~h}$ of filtration, $J_{\mathrm{f}}=\mathrm{BSA}$ flux ( $40 \mathrm{LMH}$ was taken in this study).

\section{Static protein adsorption}

Anti-fouling performance was examined using a Static protein adsorption experiments. Adsorption capacity of BSA macromolecules was evaluated by exposing the top surface of BPPO membranes (diameter $25 \mathrm{~mm})$ to a BSA solution $\left(0.5 \mathrm{mg} \mathrm{L}^{-1}\right)$ in a stirring cell. The stirring cell was then incubated in a shaker (150 rpm agitation) at $30{ }^{\circ} \mathrm{C}$ for $24 \mathrm{~h}$ to reach the adsorptiondesorption equilibrium. The amount of protein adsorbed on the top surface of membranes was calculated from the reduction concentration of BSA solution using the $\mathrm{f}$ eqn $(8):{ }^{55-57}$

$$
Q=\frac{\left(C_{\mathrm{a}}-C_{\mathrm{b}}\right) V}{A}
$$

where $Q=$ protein adsorbed $\left(\mu \mathrm{g} \mathrm{cm}{ }^{-2}\right), C_{\mathrm{b}}=$ final concentration of BSA ( $\left.\mathrm{g} \mathrm{L}^{-1}\right), A=$ area of membranes $\left(\mathrm{cm}^{2}\right), V=$ volume of the 
BSA solution (L). The concentration of BSA was determined based on the absorbance at $280 \mathrm{~nm}$ using a UV spectroscope (UV mini-1240 spectrophotometer, Shimadzu, Japan). The results shown are the average of the protein adsorption on three separate samples. After static adsorption, the flux for the fouled membrane was recorded, before the resulting BSA-fouled membranes were physically and chemically cleaned and the flux was recorded again. The flux recovery ratio was calculated again by comparing the flux before and after physical and chemical cleaning.

\section{Results and discussion}

The FTIR-ATR spectroscopy revealed the extent of chemical reaction between DETA and the BPPO UF membranes, as shown in Fig. 1.

All the BPPO UF membranes showed the main characteristic peak at $1469 \mathrm{~cm}^{-1}$ which is attributed to stretching vibrations of $\mathrm{C}=\mathrm{C}$ of benzene. ${ }^{46}$ The $\mathrm{C}-\mathrm{Br}$ stretching peak at $630 \mathrm{~cm}^{-1}$ displayed only minor changes after grafting, ${ }^{46}$ evidence that the reaction with DETA was limited to the top surface of BPPO UF membranes. After grafting, a series of new peaks emerged at 664 $\mathrm{cm}^{-1}, 1646.5 \mathrm{~cm}^{-1}$, and $1535 \mathrm{~cm}^{-1}$ assigned to the $\mathrm{N}-\mathrm{H}$ wagging, secondary amine $\left(\mathrm{R}-\mathrm{NH}_{2}\right)$ and $\mathrm{R}_{2} \mathrm{NH}$ deformation vibrations of DETA respectively. The results of FTIR-ATR spectra confirm that diethylenetriamine was successfully grafted to the surface of BPPO UF membranes and not reversibly adsorbed onto the membrane.

Surface hydrophilicity is very important factor in the antifouling properties and has a direct effect on the pure water flux (PWF) and anti-fouling performance of membranes. Reductions to the water contact angle of membranes are indicative of higher surface hydrophilicity and vice versa. ${ }^{58,59}$

Fig. 2 shows that the contact angle decreased significantly with DETA grafting period from the unmodified BPPO UF membranes contact angle $73^{\circ}$. These results indicate that the amount of DETA on the top surface of UF BPPO membranes increased with grafting period and that surface-attached DETA enhanced the hydrophilicity of BPPO membranes.

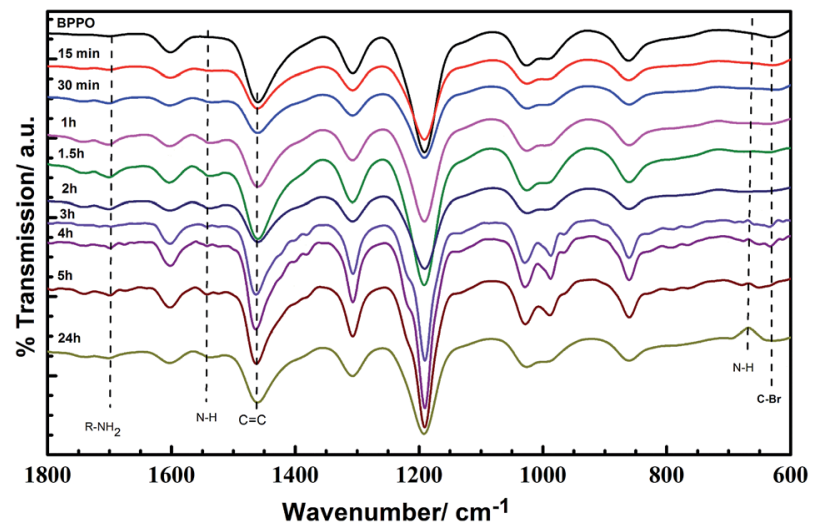

Fig. 1 FTIR-ATR spectra for BPPO and DETA-modified membranes. The time indicated for each spectra is the duration of DETA-grafting.

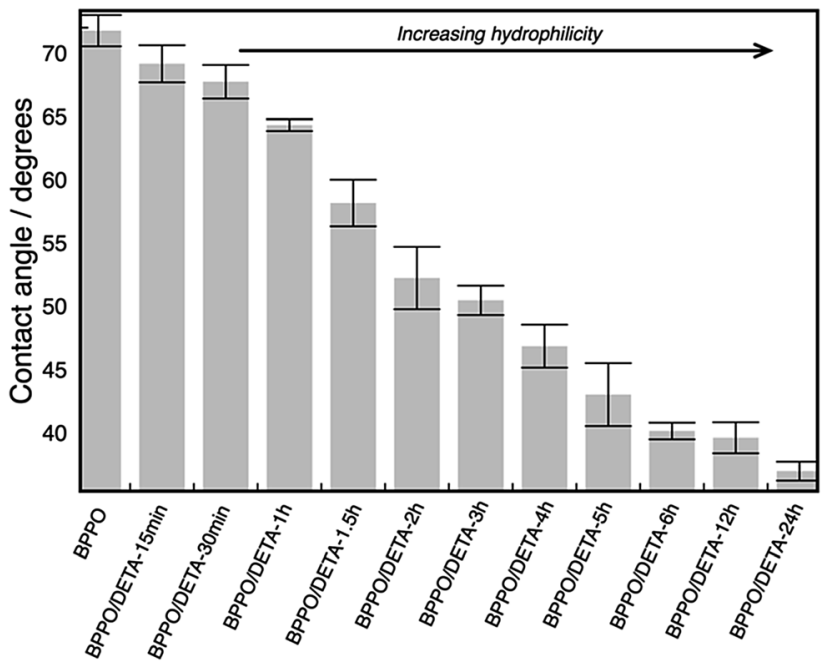

Fig. 2 Contact angle for BPPO and DETA-modified membranes with different grafting durations, leading to increased hydrophilicity. The bar height is the average of five contact angle measurements and the error bars represent $+/$ - one standard deviation.

Pure water flux and rejection are two important parameters for applications of ultrafiltration membranes. Fig. 3 shows the measurements of pure water flux (PWF) for the unmodified and modified BPPO membranes. Pure water flux (PWF) for the unmodified BPPO membranes was 197 LMH. Each of the modified BPPO membranes displayed a notable decrease in flux, with the greatest reduction of $59 \%$ observed in the membrane grafted for 24 hours.

This can be explained by DETA molecules blocking or be covering the large pores within the membrane, leading to significant flux decline; a theory confirmed by the smaller pore size of the composite BPPO, as shown in Fig. 4.

The flux is generally determined by porosity of the entire membrane, pore size and thickness of membranes. ${ }^{60}$ As such,

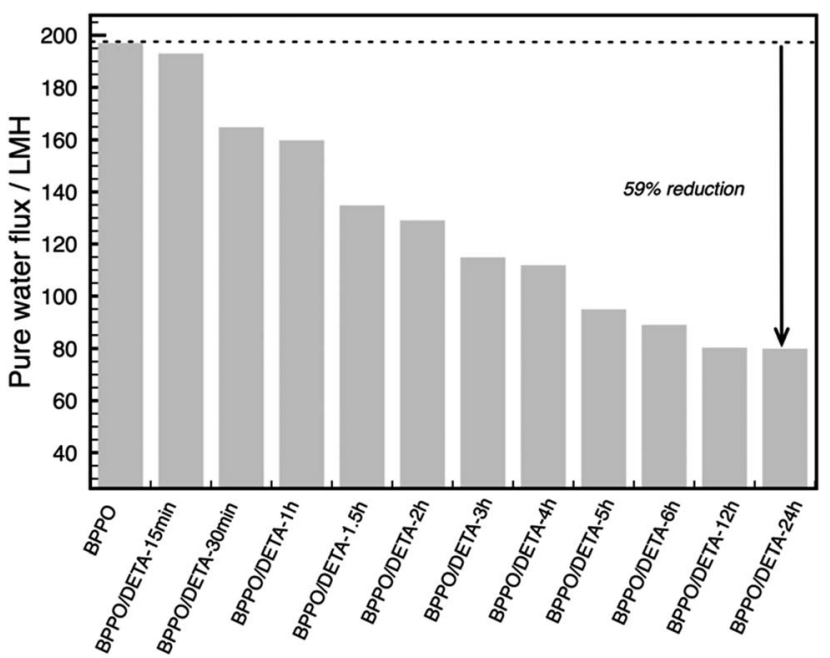

Fig. 3 Pure water flux through BPPO and DETA-modified membranes. At the maximum grafting duration of $24 \mathrm{~h}$, the pure water flux is reduced by $59 \%$ compared to the unmodified BPPO membrane. 


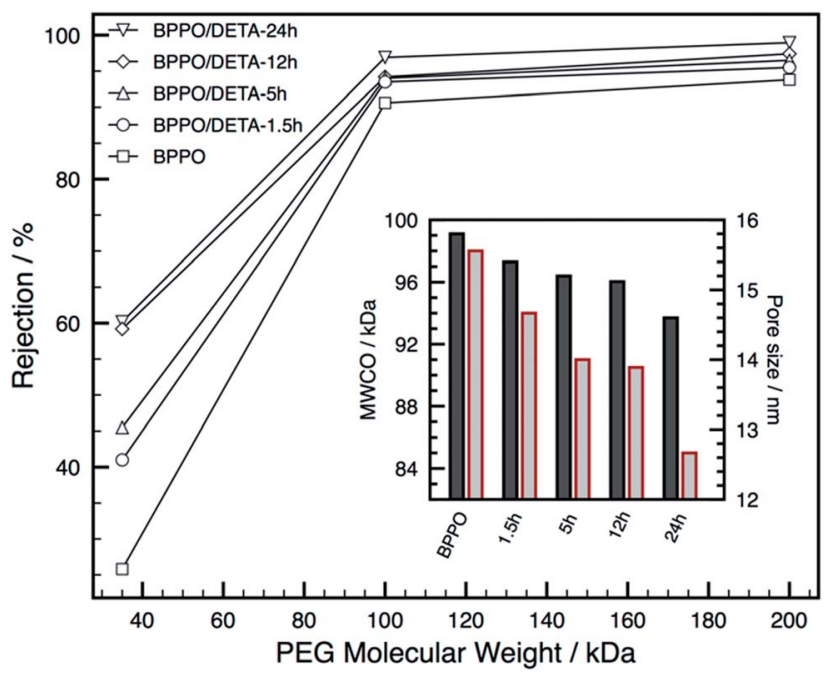

Fig. 4 Rejection of PEG (25, 100 and $200 \mathrm{kDa})$ for BPPO and DETAmodified BPPO membranes. Inset show the calculated molecular weight cut-off for each membrane (grey), as well as the calculated pore size (red).

a lower pure water flux and higher retention rate are to be expected from the surface modification procedure.

SEM images of the membrane surfaces (Fig. S1 $\uparrow$ shows the top surface, Fig. S2† shows the bottom surface) do not show any apparent change in surface morphology, suggesting that the pore filling by DETA is mostly within the pore network, and is

Table 1 Porosity and pore size of BPPO and BPPO/DETA composite membranes

\begin{tabular}{lll}
\hline Membrane & Porosity (\%) & Pore size (nm) \\
\hline BPPO & 70.6 & 15.8 \\
BPPO/DETA-15 min & 69.0 & 15.5 \\
BPPO/DETA-30 min & 65.8 & 15.1 \\
BPPO/DETA-1 h & 64.3 & 15.5 \\
BPPO/DETA-1.5 h & 63.0 & 15.4 \\
BPPO/DETA-5 h & 61.3 & 15.2 \\
BPPO/DETA-24 h & 55.6 & 14.6
\end{tabular}

a coating of the internal pore surface (as opposed to complete pore blockage). Therefore, the pore wall of BPPO will be modified by DETA, leading to decrease the pore size and performance of membranes. This agrees with the observation that in the DETA-treated membranes the pure water flux decreases steadily as the treatment duration increases (Fig. 3).

Pore size and molecular weight cut-off for pristine and composite BPPO membranes was evaluated by the rejection of PEG. Molecular weight cut-off (MWCO) was calculated based on a polyethylene glycol rejection rate of $90 \%$, which was then used to calculate the pore size of each membrane using eqn (2). The unmodified BPPO membrane showed a MWCO of $98 \mathrm{kDa}$, whilst the composite BPPO membranes showed a gradual decrease in MWCO that should be attributed to the decrease in the pore size of the active layer of membranes compared to the pristine BPPO membranes Table 1. Membrane resistances and recovery ratios measured and calculated from membrane fouling experiments for BPPO and BPPO/DETA composite membranes.

The pore size of composite membranes could also be reduced by DETA cross-linking BPPO chains, which would decrease the number and the size of the pores in the top surface of the composite membranes. Consistent with our other observations, porosity calculated according to eqn (1), confirmed that surface coating with DETA decreased pore size and pore volume of BPPO membranes. Table 1 shows that membrane porosity decreased from $70.6 \%$ to $55.6 \%$ after a 24 h DETA treatment, indicative of a partial filling of the accessible pores with DETA.

To quantitatively examine the membrane fouling performance, total filtration resistance $\left(R_{\mathrm{t}}\right)$ is the sum of intrinsic membrane resistance $\left(R_{\mathrm{m}}\right)$ (related to the membrane properties), reversible resistance $\left(R_{\mathrm{r}}\right)$ (due to the external deposition of pollutants the membrane surface), irreversible resistance $\left(R_{\mathrm{ir}}\right)$ (due to the strong adherence of pollutants on the membrane surface) were calculated using eqn (4)-(7) in the experimental section. The results of membrane resistances are presented in Table 2.

Detailed analysis showed that the DETA-modified membranes exhibited significantly higher reversible fouling

Table 2 Membrane resistances and recovery ratios measured and calculated from membrane fouling experiments for BPPO and BPPO/DETA composite membranes

\begin{tabular}{lccccc}
\hline Membrane & $R_{\mathrm{m}} \times 10^{9}$ & $R_{\mathrm{ir}} \times 10^{9}$ & $R_{\mathrm{r}} \times 10^{9}$ & $R_{\mathrm{t}} \times 10^{9}$ & $R_{\mathrm{r}} / R_{\mathrm{t}}$ \\
\hline BPPO & $5.07 \pm 0.63$ & $4.12 \pm 0.21$ & $5.19 \pm 0.31$ & 14.39 & 0.36 \\
BPPO/DETA-15 min & $5.23 \pm 0.57$ & $2.38 \pm 0.41$ & $5.02 \pm 0.61$ & 12.63 & 0.28 \\
BPPO/DETA-30 min & $6.06 \pm 0.23$ & $2.43 \pm 0.58$ & $6.52 \pm 0.99$ & 15.01 & 0.39 \\
BPPO/DETA-1 h & $6.25 \pm 0.55$ & $2.08 \pm 0.32$ & $7.18 \pm 1.1$ & 15.51 & 0.43 \\
BPPO/DETA-1.5 & $7.41 \pm 0.41$ & $1.52 \pm 0.71$ & $7.30 \pm 1.67$ & 16.23 & 0.46 \\
BPPO/DETA-2 h & $7.74 \pm 0.62$ & $1.38 \pm 0.5$ & $8.36 \pm 0.88$ & 17.48 & 0.45 \\
BPPO/DETA-3 h & $8.36 \pm 0.11$ & $0.77 \pm 0.01$ & $9.61 \pm 0.97$ & 18.70 & 0.48 \\
BPPO/DETA-4 h & $8.94 \pm 0.23$ & $0.34 \pm 0.03$ & $10.71 \pm 0.3$ & 19.90 & 0.51 \\
BPPO/DETA-5 h & $10.53 \pm 0.2$ & $0.28 \pm 0.06$ & $10.44 \pm 1.54$ & 21.25 & 0.53 \\
BPPO/DETA-6 h & $11.24 \pm 0.33$ & $0.17 \pm 0.02$ & $11.81 \pm 0.81$ & 23.22 & 0.09 \\
BPPO/DETA-12 h & $12.24 \pm 0.92$ & $0.1 \pm 0.01$ & $11.21 \pm 2.1$ & 23.50 & 0.04 \\
BPPO/DETA-24 h & $12.54 \pm 0.51$ & $0.11 \pm 0.001$ & $9.10 \pm 0.59$ & 21.75 & 0.017 \\
& & & 0.013 \\
\end{tabular}


$\left(R_{\mathrm{r}}\right)$ compared to irreversible fouling $\left(R_{\mathrm{ir}}\right)$. It is postulated that due to the smaller pore size of the DETA-modified membranes (consistent with the decreased pure water flux discussed earlier) the higher trans-membrane pressure (TMP) required to achieve constant flow during the fouling test, lead to greater irreversible fouling. However, a positive interpretation of this result is that the DETA-modified membranes can be readily and almost completely regenerated using physical and/or chemical cleaning. For all of the composite membranes, the $\left(R_{\mathrm{r}} / R_{\mathrm{t}}\right)$ ratio is considerably higher than $\left(R_{\mathrm{ir}} / R_{\mathrm{t}}\right)$ as compared to the pristine BPPO membrane which that had a similar value. Hydrophilic surfaces usually resist protein adsorption and deposition by hydrophobic interaction, explaining the DETA modified BPPO higher anti-fouling properties. The results of intrinsic membrane resistance $\left(R_{\mathrm{m}}\right)$ were consistent with the results of pore size. This outcome may be attributed to the fact that the intrinsic membrane resistance $\left(R_{\mathrm{m}}\right)$ was relied highly on the pore sizes of membranes. If the pore size of membranes increases after modification, the $R_{\mathrm{m}}$ decreases. ${ }^{61}$

Likewise, static protein adsorption is one of the most important indicators for measuring the anti-fouling performance of membranes. The results of static protein adsorption are presented in Table 3 where it can be seen that the adsorption of protein decreased from $17.8 \mu \mathrm{g} \mathrm{cm} \mathrm{cm}^{-2}$ for pristine BPPO to $17.1 \mu \mathrm{g} \mathrm{cm} \mathrm{cm}^{-2}$ after treatment with DETA for $15 \mathrm{~min}$; a reduction that continues monotonically to just $6.0 \mu \mathrm{g} \mathrm{cm} \mathrm{cm}^{-2}$ $\mathrm{BPPO} / \mathrm{DETA}-24 \mathrm{~h}$. In a consistent manner, the flux recovery ratio (FRR) increases from $40.3 \%$, for the untreated BPPO membrane, to $95.9 \%$ for the $24 \mathrm{~h}$ treated membrane. These results confirm the DETA-grafted BPPO membranes showed excellent anti-fouling properties, achieved through the facile through modification.

Here, enhanced anti-fouling performance is generated by surface hydrophilicity of membrane surface. ${ }^{59}$ Hydrophilic surfaces can adsorb water molecules and form a hydrated layer and steric hindrance on the surface of membranes, which significantly prevents the adsorption of protein and other pollutants agents on the membrane surfaces. ${ }^{61}$

Consequently, the flux of the BPPO/DETA-24 h membrane can be almost completely recovered, unlike the unmodified

Table 3 Static protein adsorption and flux recovery ratio for BPPO and BPPO/DETA composite membranes

\begin{tabular}{lll}
\hline Membrane & $\begin{array}{l}\text { Static protein } \\
\text { adsorption }\left(\mu \mathrm{cm}^{-2}\right)\end{array}$ & $\begin{array}{l}\text { Flux recovery } \\
\text { ratio }(\%)\end{array}$ \\
\hline BPPO & 17.8 & 40.3 \\
BPPO/DETA-15 min & 17.1 & 48.3 \\
BPPO/DETA-30 min & 16.5 & 63.0 \\
BPPO/DETA-1 h & 15.3 & 70.8 \\
BPPO/DETA-1.5 h & 13.6 & 80.3 \\
BPPO/DETA-2 h & 11.7 & 81.3 \\
BPPO/DETA-3 h & 10.2 & 83.6 \\
BPPO/DETA-4 h & 9.3 & 86.4 \\
BPPO/DETA-5 h & 8.6 & 88.4 \\
BPPO/DETA-6 h & 7.7 & 90.6 \\
BPPO/DETA-12 h & 6.5 & 93.2 \\
BPPO/DETA-24 h & 6.0 & 95.9
\end{tabular}

$\mathrm{BPPO}$, as adsorbed protein is loosely bound and more readily removed from the hydrophilic DETA surface of treated BPPO membranes.

\section{Conclusions}

In this article, we report the grafting of diethylenetriamine (DETA) to the top surface of BPPO membranes without pretreatments or added cross-linking agent. Characterisation of the resulting BPPO/DETA membranes highlight that although DETA causes a reduction in the porosity and pure water flux, the rejection rate was improved. Further, as a result of introducing DETA's polar groups to the membrane surface, hydrophilicity of the modified membranes increased and BPPO's interaction with foulants at the membrane surface was reduced. These features result in the composite DETA/BPPO membranes having a much higher flux recovery ratio (almost 100\%) than the pristine BPPO membranes. Although the flux is reduced by DETA modification, the improvement in anti-fouling performance promise to provide much greater operating lifetimes for BPPO membranes utilised for water and waste water treatment.

\section{Acknowledgements}

Muayad al-Shaeli acknowledges scholarship support from the Iraqi Government. Bradley Ladewig acknowledges funding support from Imperial College London, including for open access publication charges.

\section{References}

1 W. Chen, Y. Su, J. Peng, X. Zhao, Z. Jiang, Y. Dong, Y. Zhang, Y. Liang and J. Liu, Environ. Sci. Technol., 2011, 45, 65456552.

2 M. A. Shannon, P. W. Bohn, M. Elimelech, J. G. Georgiadis, B. J. Marĩas and A. M. Mayes, Nature, 2008, 452, 301-310.

3 W. Guo, H. H. Ngo and J. Li, Bioresour. Technol., 2012, 122, 27-34.

4 P. Le-Clech, V. Chen and T. A. G. Fane, J. Membr. Sci., 2006, 284, 17-53.

5 J. Mansouri, S. Harrisson and V. Chen, J. Mater. Chem., 2010, 20, 4567-4586.

6 J. Peng, Y. Su, W. Chen, X. Zhao, Z. Jiang, Y. Dong, Y. Zhang, J. Liu and X. Fan, Ind. Eng. Chem. Res., 2013, 52, 1313713145.

7 A. Ramesh, D. J. Lee, M. L. Wang, J. P. Hsu, R. S. Juang, K. J. Hwang, J. C. Liu and S. J. Tseng, Sep. Sci. Technol., 2006, 41, 1345-1370.

8 D. Rana and T. Matsuura, Chem. Rev., 2010, 110, 2448-2471. 9 Y. F. Yang, Y. Li, Q. L. Li, L. S. Wan and Z. K. Xu, J. Membr. Sci., 2010, 362, 255-264.

10 M. Yao, B. Ladewig and K. Zhang, Desalination, 2011, 278, 126-131.

11 M. Yao, K. Zhang and L. Cui, Desalination, 2010, 259, 11-16.

12 J. L. Acero, F. J. Benitez, F. J. Real and C. García, Sep. Purif. Technol., 2009, 65, 322-330. 
13 K. Moons and B. Van der Bruggen, Desalination, 2006, 199, 245-247.

14 T. Barroso, M. Temtem, T. Casimiro and A. Aguiar-Ricardo, J. Supercrit. Fluids, 2011, 56, 312-321.

15 M. J. Han, G. N. B. Baroña and B. Jung, Desalination, 2011, 270, 76-83.

16 Z. Q. Tang, W. Li, J. Zhou, H. Y. Yu, L. Huang, M. G. Yan, J. S. Gu and X. W. Wei, Sep. Purif. Technol., 2009, 64, 332-336.

17 S. J. Lee, M. Dilaver, P. K. Park and J. H. Kim, J. Membr. Sci., 2013, 432, 97-105.

18 P. D. Peeva, T. Knoche, T. Pieper and M. Ulbricht, Ind. Eng. Chem. Res., 2012, 51, 7231-7241.

19 P. D. Peeva, N. Million and M. Ulbricht, J. Membr. Sci., 2012, 390-391, 99-112.

20 H. Susanto, A. Roihatin, N. Aryanti, D. D. Anggoro and M. Ulbricht, Mater. Sci. Eng., C, 2012, 32, 1759-1766.

21 Z. Wang, H. Yu, J. Xia, F. Zhang, F. Li, Y. Xia and Y. Li, Desalination, 2012, 299, 50-54.

22 F. Zhang, W. Zhang, Y. Yu, B. Deng, J. Li and J. Jin, J. Membr. Sci., 2013, 432, 25-32.

23 J. Zhang, Z. Xu, M. Shan, B. Zhou, Y. Li, B. Li, J. Niu and X. Qian, J. Membr. Sci., 2013, 448, 81-92.

24 G. Kang, M. Liu, B. Lin, Y. Cao and Q. Yuan, Polymer, 2007, 48, 1165-1170.

25 M. Ulbricht, H. Matuschewski, A. Oechel and H. G. Hicke, J. Membr. Sci., 1996, 115, 31-47.

26 L. E. S. Brink, S. J. G. Elbers, T. Robbertsen and P. Both, J. Membr. Sci., 1993, 76, 281-291.

27 Y. C. Chiag, Y. Chang, W. Y. Chen and R. C. Ruaan, Langmuir, 2012, 28, 1399-1407.

28 S. Yu, Z. Lü, Z. Chen, X. Liu, M. Liu and C. Gao, J. Membr. Sci., 2011, 371, 293-306.

29 S. Pal, S. K. Ghatak, S. De and S. DasGupta, J. Membr. Sci., 2008, 323, 1-10.

30 I. Sadeghi, A. Aroujalian, A. Raisi, B. Dabir and M. Fathizadeh, J. Membr. Sci., 2013, 430, 24-36.

31 M. L. Steen, L. Hymas, E. D. Havey, N. E. Capps, D. G. Castner and E. R. Fisher, J. Membr. Sci., 2001, 188, 97-114.

32 T. Vladkova, P. Atanasova, S. Petrov and P. Dineff, High Energy Chem., 2013, 47, 346-352.

33 H. Y. Yu, L. Q. Liu, Z. Q. Tang, M. G. Yan, J. S. Gu and X. W. Wei, J. Membr. Sci., 2008, 311, 216-224.

34 Y. Wang, J. H. Kim, K. H. Choo, Y. S. Lee and C. H. Lee, J. Membr. Sci., 2000, 169, 269-276.

35 L. P. Zhu, B. K. Zhu, L. Xu, Y. X. Feng, F. Liu and Y. Y. Xu, Appl. Surf. Sci., 2007, 253, 6052-6059.

36 J. Kim and B. Van Der Bruggen, Environ. Pollut., 2010, 158, 2335-2349.
37 Y. Feng, X. Lin, H. Li, L. He, T. Sridhar, A. K. Suresh, J. Bellare and H. Wang, Ind. Eng. Chem. Res., 2014, 53, 14974-14981.

38 L. Jiang, X. Lin, J. Ran, C. Li, L. Wu and T. Xu, Chin. J. Chem., 2012, 30, 2241-2246.

39 B. Tang, T. Xu, M. Gong and W. Yang, J. Membr. Sci., 2005, 248, 119-125.

40 T. Xu, D. Wu and L. Wu, Prog. Polym. Sci., 2008, 33, 894-915.

$41 \mathrm{H}$. Wu, B. Tang and P. Wu, J. Membr. Sci., 2010, 362, 374-383.

42 X. Lin, X. Liang, S. D. Poynton, J. R. Varcoe, A. L. Ong, J. Ran, Y. Li, Q. Li and T. Xu, J. Membr. Sci., 2013, 443, 193-200.

43 X. Lin, J. R. Varcoe, S. D. Poynton, X. Liang, A. L. Ong, J. Ran, Y. Li and T. Xu, J. Mater. Chem. A, 2013, 1, 7262-7269.

44 X. Lin, L. Wu, Y. Liu, A. L. Ong, S. D. Poynton, J. R. Varcoe and T. Xu, J. Power Sources, 2012, 217, 373-380.

45 J. Zheng, L. Li, H. K. Tsao, Y. J. Sheng, S. Chen and S. Jiang, Biophys. J., 2005, 89, 158-166.

46 X. Lin, K. Wang, Y. Feng, J. Z. Liu, X. Fang, T. Xu and H. Wang, J. Membr. Sci., 2015, 482, 67-75.

47 L. Yang, B. Tang and P. Wu, J. Mater. Chem. A, 2014, 2, 18562-18573.

48 H. Wang, D. R. Paul and T. S. Chung, J. Membr. Sci., 2013, 430, 223-233.

49 S. P. Nunes, M. L. Sforça and K. V. Peinemann, J. Membr. Sci., 1995, 106, 49-56.

50 C. A. Smolders, A. J. Reuvers, R. M. Boom and I. M. Wienk, J. Membr. Sci., 1992, 73, 259-275.

51 C. Feng, R. Wang, B. Shi, G. Li and Y. Wu, J. Membr. Sci., 2006, 277, 55-64.

52 N. Li, C. Xiao, S. An and X. Hu, Desalination, 2010, 250, 530537.

53 Y. Lu, S. L. Yu and L. L. Meng, J. Harbin Inst. Technol., 2009, 41, 64-69.

54 A. Razmjou, J. Mansouri and V. Chen, J. Membr. Sci., 2011, 378, 73-84.

55 F. Li, J. Meng, J. Ye, B. Yang, Q. Tian and C. Deng, Desalination, 2014, 344, 422-430.

56 B. P. Tripathi, N. C. Dubey and M. Stamm, J. Membr. Sci., 2014, 453, 263-274.

57 R. Zhou, P. F. Ren, H. C. Yang and Z. K. Xu, J. Membr. Sci., 2014, 466, 18-25.

58 J. Hong and Y. He, Desalination, 2014, 332, 67-75.

59 C. Zhao, X. Xu, J. Chen and F. Yang, J. Environ. Chem. Eng., 2013, 1, 349-354.

60 S. J. Oh, N. Kim and Y. T. Lee, J. Membr. Sci., 2009, 345, 1320.

61 C. Wang, R. Feng and F. Yang, J. Colloid Interface Sci., 2011, 357, 273-279. 